\title{
A new academical village
}

\author{
William Cloud
}

Published online: 6 December 2008

(C) Springer Science+Business Media, LLC 2008

When the rich learning environment of inpatient stays is completely plowed under, where can students be exposed to the hidden curriculum of a transparent clinical decisionmaking process [1]? Its remaining habitat is the small community practice.

More patients are receiving outpatient community care. Although outpatient educational settings have their limitations (no nearby clinical and basic research, no academic culture, and no faculty consultative "village") [2] revenue considerations are diluting teaching and research [3].

As a private solo practitioner of general surgery in a small town (population 17,000) for the past 7 years, I have had the close personal experience of another phenomenon: the disappearance of the general surgery workforce $[4,5]$. There is an increasing majority of surgical residents going onto subspecialty fellowships. In urban areas, general surgeons' scope of practice is limited by this burgeoning supply of subspecialist surgeons [6]. The other effect of the shortage of rural surgeons is a considerable wealth of clinical experience, including endoscopy. These small communities cannot support subspecialty practices.

This confluence of factors results in a unique opportunity for academic medical centers, rural surgeons, and students and residents. The small practice environment allows close personal observation of the clinical decisionmaking process. The surgical experience is intimate and seamless.

Indeed, this model offers the opportunity for the establishment of a continuum of competency involving students, residents, and practising alumni [7]. With email, text messaging, web conferencing, podcasts, and a created electronic medical records (EMR) interface, the issues of specialty consultation, conferences and lectures, and teaching and learning assessment can be successful at a distance. Academic faculty and administration must be committed to flexibility, and community physicians must be committed to the educational process. As a rural surgeon I am ready to be part of this solution and hope we are all ready to make this bold move.

\section{References}

1. Institute of Medicine Report: Academic Health Centers: Leading Change in the 21st Century Board on Health Care Services. Linda T. Kohn (ed). National Academy, 2003. p. 52

2. Institute of Medicine Report: Academic Health Centers: Leading Change in the 21st Century Board on Health Care Services. Linda T. Kohn (ed). National Academy, 2003. p. 54

3. Ludmerer KM (2004) The development of American medical education from the turn of the century to the era of managed care. Clin Orthop Relat Res 422:256-262

4. Lynge DC (2008) Rural general surgeons: manpower and demographics. Surg Endosc 22:1593-1594

5. Zuckerman RS (2008) Rural surgery and surgical education. Surg Endosc 22:1592

6. Ritchie WP, Rhodes RS, Biester TW (1999) Work loads and practice patterns of general surgeons in the US, 1995-1997. A report from the American Board of Surgery. Ann Surg 230:533543

7. Institute of Medicine Report: Health Professions Education: A Bridge to Quality. Ann C. Greiner, Elisa Knebel, Editors, Committee on the Health Professions Education Summit, National Academy, 2003, p. 5
W. Cloud $(\bowtie)$

Surgery Department, Grace Hospital, Morganton, NC, USA

e-mail: drcloud@bellsouth.net 